1. MPhil Sociology

Institute of Social and Cultural

Studies

2. M.Phil Sociology

Scholars at the Institute of Social and Cultural Studies, University of the Punjab, Lahore, Pakistan

3. M.Phil Sociology

Scholars at the Institute of Social and Cultural Studies, University of the Punjab, Lahore, Pakistan

4. M.Phil Sociology

Scholars at the Institute of Social and Cultural Studies, University of the Punjab, Lahore, Pakistan

5. PhD

Institute of Social and Cultural Studies, University of the Punjab, Lahore, Pakistan

\section{Correspondence Address:}

Safdar Abbas

Institute of Social and Cultural Studies,

University of the Punjab, LahorePakistan

abbas.safdar@hotmail.com

Article received on:

12/08/2014

Accepted for publication:

22/10/2014

Received after proof reading:

15/12/2014

\title{
KNOWLEDGE AND CONCEPTION OF TUBERCULOSIS;
} AMONG REPRODUCTIVE AGED WOMEN: A QUANTITATIVE ANALYSIS BASED ON PAKISTAN DEMOGRAPHIC AND HEALTH SURVEY

\author{
Safdar Abbas ${ }^{1}$, Jacob Malik ${ }^{2}$, Noman Issac ${ }^{3}$, Rabia Safdar ${ }^{4}$, Dr. Bushra Yasmeen ${ }^{5}$
}

ABSTRACT... With the very high incident of tuberculosis, Pakistan ranks fifth globally among the 22 high tuberculosis risk countries. Amongst other factors, socio-demographic factors play a significant role in determining "knowledge of tuberculosis" Objectives: This study used secondary data from the Pakistan Demographic and Health Survey to estimate the impact of socio-demographic factors determining the knowledge of tuberculosis and conception on how it is spread. Data Source: The relevant variables and the other parameters were extracted from the both pdf and SPSS files of PDHS. Study Design: Bi-variant cross tabulation was used to determine the level of association between the hypothesized variables using the Pearson chi-square statistic. Results: Age and wealth index showed a highly significant relationship $(p<0.0001)$ in determining the knowledge of tuberculosis. Moreover, the increasing level of education showed a decreasing trend of misconception about the spread of TB. Conclusions: Though the results of the study indicated a highly significant relationship between the sociodemographic factors and knowledge of tuberculosis, there is a dire need to launch awareness campaigns by the public and private sector organizations to enhance the level of correct knowledge and conception of large masses.

Key words: $\quad$ Tuberculosis, Pakistan DHS, and Reproductive-age women.

Article Citation: Abbas S, Malik J, Issac N, Safdar R, Yasmeen B. Knowledge and conception of tuberculosis; among reproductive aged women: a quantitative analysis based on pakistan demographic and health survey. Professional Med J 2014; $21(6): 1213-1221$.

Tuberculosis (TB) besets an acute peril to Pakistani society as it reaches epidemic proportions, leading the country to rank 5th on the list of countries with highest tuberculosis prevalence rates $^{3}$. This pernicious disease engenders almost $26 \%$ avertable deaths in adults and children in Pakistan ${ }^{1}$. Morbidity and mortality rates wreak tuberculosis the status of an essentially important health concern to be researched. Unlike the world-over trends of men bearing more of the tuberculosis burden, Pakistan and Afghanistan are the countries which have the higher disease prevalence rates among women ${ }^{3}$. Reproductive aged women, once affected by TB, are highly susceptible towards the reoccurrence of the disease ${ }^{12}$. Deaths caused by TB alone exceeded in number than all other maternal mortality deaths combined $^{12}$.Furthermore, the disease compounded with poverty and malnutrition that is usually the case in rural areas of Pakistan - aggravates the baneful consequences, comprising both medical and social implications as causing infertility, stigmatization and even ostracism in some cases ${ }^{11}$.

On one hand the fact that tuberculosis is a curable disease the health and medicine disciplines profess while on the other we see a considerable rate of TB mortality. What are the lapses? Why such a discrepancy that people tend not to seek the treatment?

Seeking answers to such questions, many researches ${ }^{2,4}$; Ministry of Inter-Provincial Coordination, $2012^{7}$ ), have attempted to explicate the reasons which lead to the negligence of patients towards having a checkup and treatment which consequently affect the TB mortality rates. The unanimous results obtained in all the aforementioned researches contend that the propensity for TB treatment directly relates to the perceived threat the disease poses - the patients had having low awareness of TB etiology, symptomatology, and prevention measures rather 
restrained or postponed a medical checkup and treatment ${ }^{10}$.

Drawing from these research findings, if knowledge about the disease is what determines the patient's propensity towards treatment then what determines the distribution of knowledge and if the knowledge is uniformly distributed among different stratums of the society? If not then what must be done to spread the knowledge more uniformly? Which stratum needs to have more awareness and which tends to have more? These are the basic questions the present study has attempted to address.

For level of awareness about TB, the research has conjectured a positive relation existing between socio-demographic conditions and level of TB awareness; the people with higher SES usually have more of TB knowledge while the poor are less informed ${ }^{8}$. Many of the researches have also shown a significant outcome relation existing between Socio-demographic conditions and the level of Tuberculosis knowledge among individuals. Anjum et al $2009^{1}$ in their research findings outline a set of socio-demographic characteristics compared against level of tuberculosis knowledge, with socio-demographic variables classified along three lines: place of residence, literacy and wealth index. Findings for place of residence and tuberculosis knowledge have shown a rural-urban disparity. Urbanites were found to be relatively more conversant about the diagnostic aspects of the disease as compared to the rural counterpart. Similarly, the literate tended to have more awareness about the disease. Wealth was also observed to be aiding acquisition of cultural capital and higher awareness about the disease, furthermore possession of wealth was able to increase the relative incidence for an individual to urbanize and his/her proclivity for formal education ${ }^{1}$.

\section{METHODS \& MATERIALS}

\section{Participants}

For the present study, data has been obtained from the Pakistan Demographic Health Survey (PDHS $^{9}$ ) 2006-07, a study commissioned by the
Government of Pakistan with the technical support of USAID and National Institute of Population Studies (NIPS). Sample size for this survey was 10024 and all of the respondents were females who were in their reproductive age group i.e. 1545 years.

\section{Extraction of Data}

The said study used cross sectional survey wherein quantitative information was collected through questionnaire. The said survey collected information regarding respondents' sociodemographic characteristics along with the information against different health indicators including fertility, family planning, infant and child mortality, reproductive health, child health, nutrition, adult and maternal mortality, and different diseases including TB. Due to the fact that the study hypothesized that socio-demographic factors determine the knowledge of TB, therefore, information regarding the same variables was excerpted from the PDHS survey report as well as the variables were taken from SPSS file of the said survey.

\section{Variable Definitions and Construction}

Independent variable used is socio-demographic factors that includes, age, place of residence, de facto place of residence, wealth index, and level of education, whereas, dependent variable, Knowledge of TB includes, heard of TB, spread of TB through different sources and respondents conception about TB curability, as operational measures. SPSS Bi-variate Analysis was employed to study the variables involved. Some variables are recoded and re-categorized for making the statistical analysis possible and see the relationship, if any exists between the hypothesized variables:

Age. This interval level variable as employed in PDH survey - with interval being 5, distributed over seven classes/categories - represented respondent's age varying amid $15-49$ years, while for our study's purpose, it is re-categorized into 3 classes with an interval of 15 i.e 15-30, 31-45, and 45 and above. This categorization didn't just make the Bivariate analysis possible but also made the 
results presentable and understandable because no respondent in the PDHS was below the age of 15 years.

Residence. This was formulated using four categories i.e. large city, small city, town and rural. Validity of the data obtained for the place (from among four mentioned) of residence relied only upon respondents self-perceived answers.

Region. This was made based on the already established political boundaries of the four main provinces of Pakistan: Khyber Pakhtonkhawa, Punjab, Sindh and Balochistan. The respondents gave a self-reported answer to establish these categories.

Education. This was divided into four categories i.e., No education, primary, secondary, and higher. These are categorized as following: no education for absence of any formal schooling, primary for classes $1-8$, secondary for classes 9 \& 10 and higher denoting education above 10th class including college and university.

Wealth Index. This, as conceptualized in DHS, divided into 5 categories i.e., lowest, low, middle, high and highest. In addition to monthly income the scale used aggregate household asset value and provision of basic facilities, such as television, car, refrigerator, shelter (dwelling's value), clean drinking water access and sanitation facilities as determinants of wealth index. Each asset was assigned a weighted factor score, put through a principle components analysis these scores were standardized. Aggregate asset score was placed against the household score. For the purpose of our studies and application of bivariate analysis the variable is re-categorized into poor, medium, and high income groups.

Spread of TB by different factors. These factors include spread by: coughing or sneezing, sharing utensils, touching a person with TB, sharing food, sexual contact and mosquito bite. One response category, spread by coughing or sneezing is recoded as one variable, "Correct Knowledge", whereas, rest of the five response categories are grouped into another, "Misconception".

\section{RESULTS}

Frequency and bi-variate cross tabulation analysis is done in SPSS. Each analysis was divided into categories based on their respective variables.

\section{Frequency}

For the total sample $(n=10024)$, a frequency table is generated (see Table 1) and percentages are calculated.

Age. The group "15 - 30" comprised the most of $47.3 \%$ of the total responses $(n=4741)$ while group " $46+$ " comprised the least of $8.7 \%(n=868)$.

Region of Pakistan. The group "Punjab" represented the most of $42.5 \%$ of the data $(n=$ 4263) while the group "Balochistan" did the least of $11.8 \%(n=1182)$.

Place of Residence. The group "Countryside" represented the most of $61.8 \%$ of the total responses ( $n=6$ 193) while "town" represented the least of $3.6 \%(n=362)$. The groups "capital, large city", "small city" and "town" when combined together to represent "urban" contain $38.2 \%$ of the total data $(n=3830)$.

Educational level. The group "no education" scored the most of $66.5 \%$ of the responses $(n=6665)$ while group "higher" scored the least of $6.6 \%(n=666)$.

\section{Cross Tabulation}

Two separate cross tabulations were executed to see the relationship of having heard of Tuberculosis (see Table II) and conception of how Tuberculosis is spread (see Table 3) against socio-demographic factors. The respondents who answered "yes" in the first cross tabulation were then checked against the correct conception of TB in the other cross tabulation.

Cross tabulation 1. Age showed a highly significant relationship $(p<0.0001)$ with having heard of Tuberculosis, declining as the groups increased in age: $46.30 \%$ of the group "15-30" had 
heard of TB $(n=4123)$ whereas $8.90 \%$ of the group "46+" ( $n=791$, see Figure 1). Region showed a highly significant relationship $(p<0.0001)$ with having heard of Tuberculosis, declining as province population size decrease: $41.80 \%$ of respondents in Punjab $(n=3716)$ whereas $12 \%$ of respondents from Balochistan had heard of TB $(n=1067)$. Place of residence showed a highly significant relationship $(p<0.0001)$ with having heard of Tuberculosis, as in the countryside (59.90\%, $n=5333$ ), being more prevalent than urban areas $(40.1 \%, n=3564)$. When viewing urban alone, knowledge declined as the size of the area decreased - large cities having more respondents having heard of TB $(20.6 \%, n=1$ 832) than a town $(3.6 \%, n=323)$. The urban population compared in percentage against the total population also has ramified the results while unawareness of large city respondents compared against its own population yields completely a different picture, wherein only 5.02\% respondents of large cities are unaware about the disease.

The statistics rest in increasing trends as it gets down to small cities followed by towns and countryside. $13.88 \%$ of total country side population is unaware about the disease. Hence, as is moves downward from cities to countryside the amount of respondents unaware about the disease multiply by more than 2.5. The Wealth Index showed a highly significant relationship $(p<0.0001)$ with having heard of Tuberculosis, increasing as wealth increased. The group "Rich" has the highest percentage of "yes" (43.3\%, $\mathrm{n}=38$ ) and "Poor" has the highest percentage of "no" $(60.2 \%, n=678)$. As wealth increased, having knowledge of TB increased notably when comparing rich (43.3\%) with poor $(37.2 \%)$. As wealth decreased, having no knowledge of TB increased very notably when comparing rich (20.3\%) to poor (60.2\%). Education showed a highly significant relationship $(p<0.0001)$; No education had the highest percentage of both "yes" (64.0\%) and "no" (86.1\%) categories among all the groups. Primary and Secondary education had near about the same percentages in "yes" category; $14.1 \%$ and $14.5 \%$ respectively.
Age showed a highly significant relationship $(p<0.0001)$ with having a misconception of how TB is spread declining as the groups increased in age: $50.8 \%$ of the group "15-30" had a misconception about TB spread whereas $7.80 \%$ of the group " $46+$ " had a misconception of how TB is spread. Region showed a highly significant relationship $(p<0.0001)$ with having a misconception of how TB is spread increasing as province population size increased: $47.70 \%$ of respondents in Punjab had a misconception of how TB is spread whereas $8.2 \%$ of respondents from Balochistan had a misconception. Place of residence showed a highly significant relationship $(p<0.0001)$ with having misconception of how TB is spread in the countryside (69\%) being more prevalent than those living in urban areas (31\%). When viewing urban alone, a misconception declined as the size of the urban decreased large cities having more respondents having a misconception of TB spread (15.10\%) than a town $(2.7 \%)$.

The Wealth Index showed a highly significant relationship $(p<0.0001)$ with having a misconception of how TB is spread decreasing as wealth increased (see Figure 4). The group "Rich" had the lower percentage of misconception (32.5\%) when compared with "Poor" (47.7\%). As wealth increased, having a correct concept of TB spread increased notably when comparing "Rich" (49.0\%) to "Poor" (32.0\%). Education showed a highly significant relationship $(p<0.0001)$; No education had the highest percentage of both "correct" (58.7\%) and "incorrect" (74.4\%) categories among all the groups. As education increased, misconception decreased; "Higher" had only a $2.9 \%$ misconception rate compared to "No Education" (74.4\%).

\section{DISCUSSION}

Descriptive and inferential analysis of the data brought forth varied findings of the present study. On the basis of certain factors which under or over represented the total population, associations were drawn to answer the questions posed in the present research. In education, 66.5\% $(n=6653)$ of all the respondents had no education, whereas 


\begin{tabular}{|c|c|c|c|}
\hline \multirow[b]{2}{*}{ Characteristics } & & \multicolumn{2}{|c|}{$\begin{array}{c}\text { Respondents } \\
(\mathrm{N}=10024)\end{array}$} \\
\hline & & $\mathrm{N}$ & $\%$ \\
\hline \multirow[t]{3}{*}{ Respondent's Age } & $15-30$ & 4741 & 47.3 \\
\hline & $31-45$ & 4414 & 44 \\
\hline & $46+$ & 868 & 8.7 \\
\hline \multirow[t]{4}{*}{ Region of Pakistan } & Punjab & 4263 & 42.5 \\
\hline & Sindh & 2716 & 27.1 \\
\hline & NWFP & 1862 & 18.6 \\
\hline & Balochistan & 1182 & 11.8 \\
\hline \multirow{4}{*}{$\begin{array}{l}\text { Respondent's place of } \\
\text { residence }\end{array}$} & Capital, large city & 1929 & 19.2 \\
\hline & Small city & 1539 & 15.4 \\
\hline & Town & 362 & 3.6 \\
\hline & Countryside & 6193 & 61.8 \\
\hline \multirow[t]{3}{*}{ Calculated Wealth Index } & Poor & 3992 & 39.8 \\
\hline & Medium & 1946 & 19.4 \\
\hline & Rich & 4085 & 40.8 \\
\hline \multirow{4}{*}{$\begin{array}{l}\text { Highest educational level } \\
\text { attained by Respondent. }\end{array}$} & No education & 6665 & 66.5 \\
\hline & Primary & 1344 & 13.4 \\
\hline & Secondary & 1348 & 13.4 \\
\hline & Higher & 666 & 6.6 \\
\hline
\end{tabular}

Table-I. Frequency of socio-demographic factors of respondents

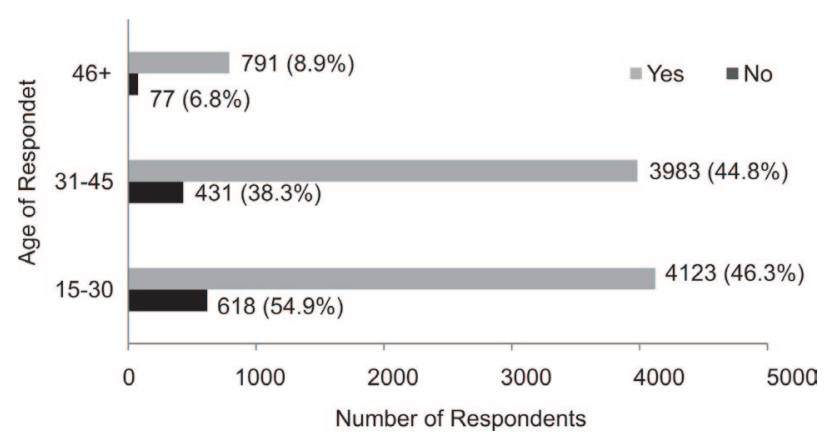

Figure-1. Bar graph showing the age of the respondents with whether the respondent has heard of Tuberculosis or not.

the next highest was primary education at $13.4 \%$ $(n=1343)$. Higher education category accounted for only $6.6 \%(\mathrm{~N}=666)$ of all respondents, and as the general assumption goes, so as the different researches corroborate ${ }^{5,10}$, education had have held a significant relationship with awareness about tuberculosis. In region, Punjab had $42.5 \%$ $(n=4252)$ of all the respondents, whereas the smaller provinces suffered from numbers considerably less than that of Punjab; Sindh the next highest only had $27.1 \%(n=2713)$. In the residence variable, over $3 / 5(61.8 \%)$ of the

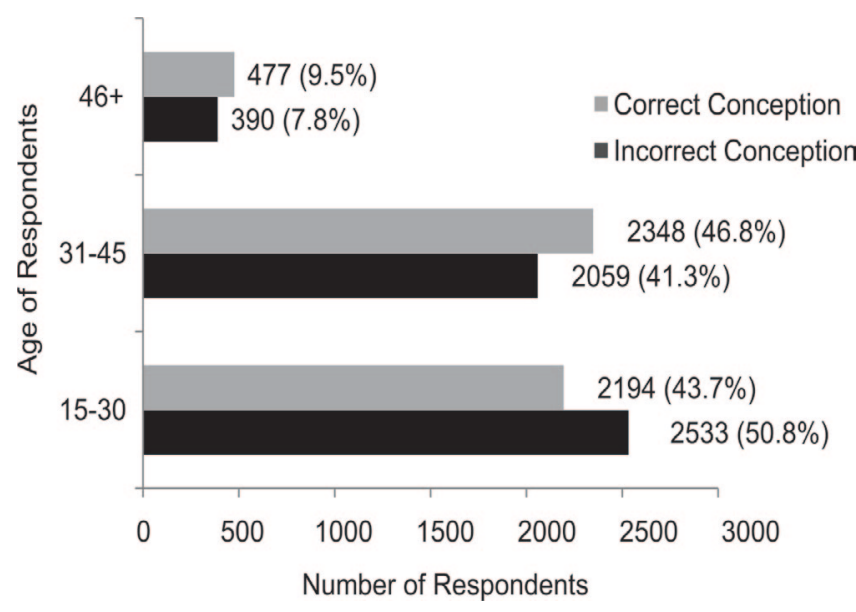

Figure-2.Bar graph showing the age of the respondents with whether the respondent had correct or incorrect conception of how Tuberculosis is spread.

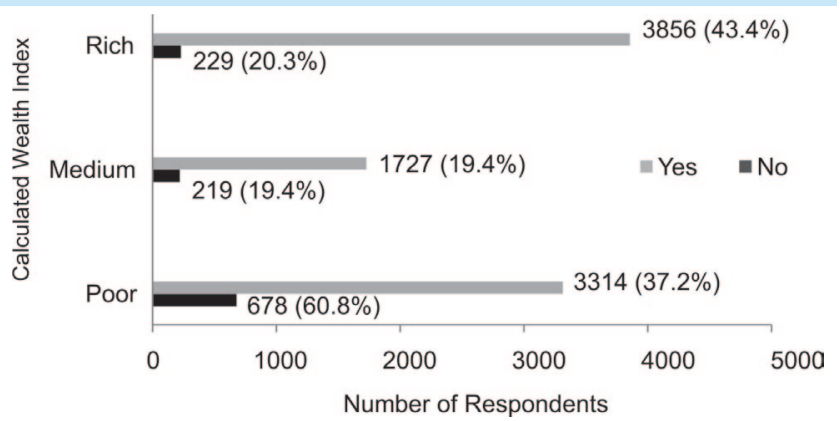

Figure-III. Bar graph showing the age of the respondents with whether the respondent had correct or incorrect conception of how Tuberculosis is spread.

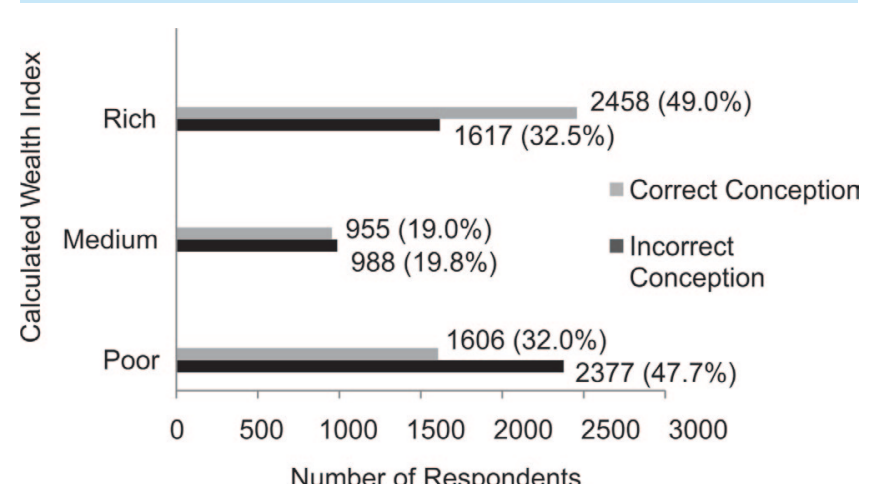

Figure-4. Bar graph showing Wealth Index Categorized for the respondents with whether the respondent had correct or incorrect conception of how Tuberculosis is spread.

respondents were from non-urban areas.

This translated to roughly 6179 rural and 3822 urban respondents if the three city categories are combined. Towns only accounted for $3.6 \%$ of the data $(n=362)$. This figure was surprising. Despite 


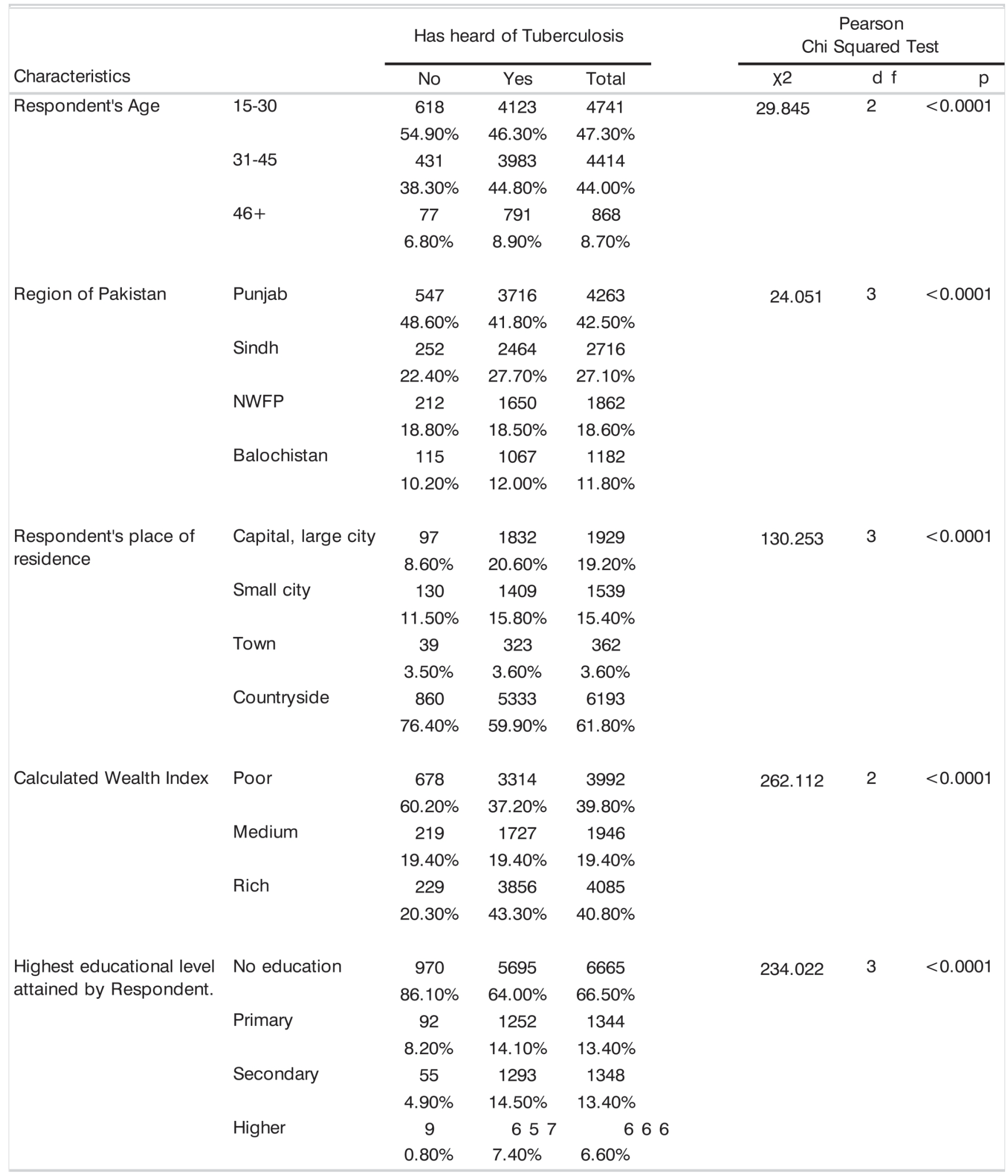

Table-II. Cross-tabulation of socio-demographic factors vs. has the respondent heard of tuberculosis Notes. $n=10024$ with occasional missing values. 


\begin{tabular}{|c|c|c|c|c|c|c|c|}
\hline \multirow[b]{2}{*}{ Characteristics } & & \multicolumn{3}{|c|}{$\begin{array}{l}\text { Correct or Incorrect conception of how } \\
\text { TB is spread. }\end{array}$} & \multicolumn{3}{|c|}{$\begin{array}{c}\text { Pearson } \\
\text { Chi Squared Test }\end{array}$} \\
\hline & & $\begin{array}{c}\text { Incorrect } \\
\text { Conception }\end{array}$ & $\begin{array}{c}\text { Correct } \\
\text { Conception }\end{array}$ & Total & $x 2$ & $d f$ & $\mathrm{p}$ \\
\hline \multirow[t]{6}{*}{ Respondent's Age } & $15-30$ & 2533 & 2194 & 4727 & 51.857 & 2 & $<0.0001$ \\
\hline & & $50.80 \%$ & $43.70 \%$ & $47.30 \%$ & & & \\
\hline & $31-45$ & 2059 & 2348 & 4407 & & & \\
\hline & & $41.30 \%$ & $46.80 \%$ & $44.10 \%$ & & & \\
\hline & $46+$ & 390 & 477 & 867 & & & \\
\hline & & $7.80 \%$ & $9.50 \%$ & $8.70 \%$ & & & \\
\hline \multirow{8}{*}{$\begin{array}{l}\text { Province of } \\
\text { Pakistan }\end{array}$} & Punjab & 2378 & 1874 & 4252 & 176.704 & 3 & $<0.0001$ \\
\hline & & $47.70 \%$ & $37.30 \%$ & $42.50 \%$ & & & \\
\hline & Sindh & 1317 & 1396 & 2713 & & & \\
\hline & & $26.40 \%$ & $27.80 \%$ & $27.10 \%$ & & & \\
\hline & NWFP & 878 & 982 & 1860 & & & \\
\hline & & $17.60 \%$ & $19.60 \%$ & $18.60 \%$ & & & \\
\hline & Balochistan & 409 & 767 & 1176 & & & \\
\hline & & $8.20 \%$ & $15.30 \%$ & $11.80 \%$ & & & \\
\hline \multirow{8}{*}{$\begin{array}{l}\text { Respondent's } \\
\text { place of residence }\end{array}$} & Capital, large city & 753 & 1172 & 1925 & 225.697 & 3 & $<0.0001$ \\
\hline & & $15.10 \%$ & $23.40 \%$ & $19.20 \%$ & & & \\
\hline & Small city & 653 & 882 & 1535 & & & \\
\hline & & $13.10 \%$ & $17.60 \%$ & $15.30 \%$ & & & \\
\hline & Town & 137 & 225 & 362 & & & \\
\hline & & $2.70 \%$ & $4.50 \%$ & $3.60 \%$ & & & \\
\hline & Countryside & 3439 & 2740 & 6179 & & & \\
\hline & & $69.00 \%$ & $54.60 \%$ & $61.80 \%$ & & & \\
\hline \multirow{6}{*}{$\begin{array}{l}\text { Calculated Wealth } \\
\text { Index }\end{array}$} & Poor & 2377 & 1606 & 3983 & 323.238 & 2 & $<0.0001$ \\
\hline & & $47.70 \%$ & $32.00 \%$ & $39.80 \%$ & & & \\
\hline & Medium & 988 & 955 & 1943 & & & \\
\hline & & $19.80 \%$ & $19.00 \%$ & $19.40 \%$ & & & \\
\hline & Rich & 1617 & 2458 & 4075 & & & \\
\hline & & $32.50 \%$ & $49.00 \%$ & $40.70 \%$ & & & \\
\hline \multirow{8}{*}{$\begin{array}{l}\text { Highest } \\
\text { educational level } \\
\text { attained by } \\
\text { Respondent. }\end{array}$} & No education & 3706 & 2947 & 6653 & 404.937 & 3 & $<0.0001$ \\
\hline & & $74.40 \%$ & $58.70 \%$ & $66.50 \%$ & & & \\
\hline & Primary & 649 & 694 & 1343 & & & \\
\hline & & $13.00 \%$ & $13.80 \%$ & $13.40 \%$ & & & \\
\hline & Secondary & 482 & 858 & 1340 & & & \\
\hline & & $9.70 \%$ & $17.10 \%$ & $13.40 \%$ & & & \\
\hline & Higher & 145 & 520 & 665 & & & \\
\hline & & $2.90 \%$ & $10.40 \%$ & $6.60 \%$ & & & \\
\hline
\end{tabular}

Table-III. Cross-tabulation of socio-demographic factors vs. correct or incorrect conception of how TB is spread

Notes. $n=10024$ with occasional missing values. 
showing a downward trend when urban areas were compared with each other, the rural variable threw off of the analysis. Since rural participation is a critical part of the "true picture", this category cannot be discounted. However, its presence makes the interpretation of the results difficult and wildly skewed the findings. Despite all the variables showing highly significance $(p<0.0001)$ relationships after conducting a Pearson Chi Square test, the actual "truth" maybe lost due to the reasons stated above for those variables.

The Age variable was very interesting. The findings suggest that many individuals in the study who were older had no knowledge of TB. This could be for any of many reasons, since has access to education, health care services or even that the prevalence in their area isolated them from learning of the existence of TB. However, the findings suggest that the older respondents overall had a greater number of individuals with correct concept of how TB is spread; inversely, incorrect concept decreased with age. This only

accounts for the first two categories, since the $45+$ group had a very small sample $(n=867$, $8.7 \%)$ compared to the $15-30$ group $(n=4727$, $47.3 \%$ ) - leading to a problem as stated in the first part of the discussion. The finding is consistent with the study of Josephat $\left(2014^{10}\right)$ wherein the results reveal an positive association existing between increasing age and correct knowledge of tuberculosis (2014).

The Wealth Index data provided remarkable findings. More money, consumer items and better living conditions an individual possesses, has a significant relationship $(p<0.0001)$ with individuals having knowledge of TB and correct concept of how TB is spread. Less money, fewer consumer items and poor living conditions has a significant relationship with individuals having either no knowledge of what TB is or having a misconception of how it is spread. The findings have been consistent with existing literature which suggest that economic factors play a significant role in determining whether individuals know about Tuberculosis and further if a misconception exists about how it is spread ${ }^{6,10}$, and suggest that economic factors play a significant role in determining whether individuals know about Tuberculosis and further if a misconception exists about how it is spread. Moreover, the Wealth Index itself shows a staggering number of individuals at the extremes; more individuals are either extremely rich or extremely poor which could reflect the present reality in Pakistan.

\section{CONCLUSIONS}

There is a significant relationship between the socio-demographic factors and knowledge of tuberculosis, specifically regarding economic (wealth index) and education factors. Majority of the respondents have misconception about the ways of spread of tuberculosis i.e. it is spread by touching, sharing utensils and food, sexual contact and by mosquito bites, especially with the age variable. Conception about spread of tuberculosis varies with the socio-demographic factors based on the extraneous factors mentioned in the discussion. Higher level of SDFs results in reduced misconception about spread of tuberculosis, except in for age, education and wealth index. Overall, more research should be done in the area of age, education and economic factors to better understand the nature of why Pakistan is plagued with such a terrible disease that is uncommon nowadays in the West.

The primary strength of this research was the benefit of a large sample size and ready access to data from the DHS. It could be assumed that even if 5 percent were missing values, it would not impact the analysis in a significant way. Data access to this level is at times difficult to collect due to the nature of the Pakistani environment and political situation, but the DHS provides a treasure trove of data, albeit a bit dated. Another strength is that the survey itself is very simple to administer and not very invasive or offensive, at least in regards to the topic of Tuberculosis; this simplicity could help reduce bias and confusion in the respondents to get to a clearer picture of what the reality actually is.

One of the major limitations of the study was that it 
did not cater the both genders i.e. males \& females and only collected information from females. Except the given possibility of some variables like; reproductive health and breastfeeding, male respondents should have been included in the study, which is certainly, an equal or perhaps more, potential group for study. Another limitation is that the response variable for the spread of TB entails multiple responses which include, spread by coughing, sharing utensils, touching a person, sharing food, sexual content, and mosquito bites. A distinctive line has not been drawn among these response sets to distinguish the correct knowledge or just misconception. Accordingly, questionnaire and data have not been collected on these lines. In case of Tuberculosis, data has not been collected about prevalence of TB which is not only a very important variable to measure the frequency of infected people but having the information of it, future research and policy level interventions could be introduced. The nature of some of the data under initial consideration was incomplete or not useable due to extreme missing values (upward of $80 \%$ ), which limited the scope of variables included. Due to the nature of the DHS itself, the questions regarding TB were fairly limited and the questionnaire itself is limited.

A suggestion for future research is that a Gender disaggregated DHS should be conducted to enhance the scope of study and that both private and public sector organizations should launch awareness campaigns and advance researches to tackle the problem of TB. Based on the findings of the study, it is recommended that government level initiatives should be taken to reduce the prevalence of TB among large masses. Additionally, in terms for future research, additional variables and analysis could be used, for example respondent's access to health care, focus on intra-urban or rural variables exclusively analyzed and country infection prevalence rates. By looking at and comparing prevalence rates, for example, some of this study's findings could yield more meaning results.

Copyright@ 22 Oct, 2014.
REFERENCES

1. Anjum, A., Daud, S., \&Mukhtar, F. Tuberculosis: Awareness about Spread and Control. Professional Medical Journal, 2009;16(1): 61. Retrieved January 2013, from http://www.theprofesional.com/ article/2009/V- 16-N-1/Prof- 13 66.pdf

2. Appraisal Mission Aide Memoire. (1997, October). Second Social Action Project, Islamabad, V-3 1.

3. Dogar, O. F., Shah, S. K., Chughtai, A. A., \&Qadeer, E. Gender disparity in tuberculosis cases in eastern and western provinces of Pakistan. BMC Infectious Diseases, 2012; Vol. 12 Issue 1, p244.

4. Gelaw, M., Genebo, T., Dejene, A., Lemma, E., \&Eyob, G. Attitude and Social Consequences of Tuberculosis in Addis Ababa, Ethopia. East African Medical Journal, 2001;382-386. Retrieved from: http://www.jpma.org.pk/ full_article_text.php?article_id $=695$.

5. Josephat, A. I. Knowledge and perception on tuberculosis transmission in Tanzania: Multinomial. Tanzania Journal of Health Research, 2014;16(1).

6. Marinac, J.C. Knowledge of tuberculosis in highrisk populations: survey of inner city minorities. International Journal of Tuberculosis and Lung Diseases., 1998;2(10): 804-10.

7. Ministry of Inter-Provincial Coordination. About TB. Retrieved from National Tuberculosis Control Programme: http://www.ntp.gov.pk/about.htm 2012.

8. Mushtaq, M. M. Urban-rural inequities in knowledge, attitudes and practices regarding tuberculosis in two districts of Pakistan's Punjab province. International Journal for Equity in Health, 2011;10(1): 1.

9. National Institute of Population Studies [Pakistan], and Macro International Inc. (2008). Pakistan Demographic and Health Survey 2006-0 7. Islamabad, Pakistan: National Institute of Population Studies and Macro International Inc.

10. Qureshi, S.A. (2008, June). Patient and health system delays: Health-care seeking behaviour among pulmonary tuberculosis patients in Pakistan. Retrieved April 05, 2014, from JPMA: http://jpma.org.pk/ full_article_text.php?article_id $=1420$

11. World Health Organization. (2009). Tuberculosis, Women and TB. Retrieved January 2013, from http://www.who.int/tb/challenges/gender/factsheet_ womenandtb.pdf

12. World Health Organization. (2013). Tuberculosis (TB). Retrieved January 2013, from World Health Organization: http://www.who.int/tb/challenges/hiv/faq/en/. 